\title{
The use of real time video magnification for the pre-clinical teaching of crown preparations
}

\author{
P. B. Robinson, ' and J. W. Lee, ${ }^{2}$
}

\begin{abstract}
Objective To investigate the effect on the undergraduate learning process of using an alternative method designed to enhance the visual demonstration of taper on full veneer crown preparations (better understanding of the value of taper on preparations early in the teaching programme in restorative dentistry).

Design A comparison between the conventional teaching of full veneer crown preparations and the same teaching with the additional use of a magnified real time video display using a surgical microscope was investigated in this study.

Outcome measures The degree of taper was measured for replica full crown preparations and results compared between different cohorts of undergraduates and experimental conditions.

Result Undergraduates taught using the real time video produced more accurately tapered preparations. This ability was retained over one year.

Conclusions A possible explanation for the result was that the use of magnification improved the undergraduates' precise understanding of taper by enhancing their ability to evaluate this critical measurement during the teaching process.
\end{abstract}

$\mathrm{D}$ uring the introduction to clinical practice, pre-clinical undergraduates at this institute are taught the full veneer crown (FVC) preparation using plastic replica teeth, articulated, and set in a manikin. At such an early stage in their course they find this exercise difficult, particularly with the placement of an appropriate convergence or taper on the preparation. Note that the term 'taper' here is used in accordance with the recommendation of Rosenstiel. ${ }^{1}$

The optimal taper for a preparation is a function of many factors, that include the fit of the crown, the shape of the preparation to resist displacement, the occlusion, the type of cement used, the internal surface finish of the preparation and the surface of the restoration. Selection of an appropriate

\footnotetext{
${ }^{1}$ Senior Lecturer, Consultant in Conservative Dentistry, Guy's, King's and St Thomas' Schools of Medicine and Dentistry and Biomedical Sciences, The Dental Institute, Bessemer Road, London SE5 9RS.

${ }^{2}$ Lecturer in Medical Electronics, Department of

Medical Engineering and Physics, Guy's, King's and St

Thomas' Schools of Medicine and Dentistry, Bessemer Road, London SE5 9RS

${ }^{*}$ Correspondence to name and address.

REFEREED PAPER

Received 19.03.99; Accepted 15.08.00
}

taper is also dependent on the morphology of the tooth being prepared. The preferred angle for preparation is reported to be in the range 3-14 degrees. ${ }^{2}$ The uncertainty is associated with the factors mentioned above together with the difficulty of visualising the acute angle in the clinical situation and the determination to avoid undercutting. The recommended taper angle for teaching in this Institute is 7 degrees. This has been found suitable for the minimisation of undercuts in the clinic as well as in the laboratory and also to optimise retention. Further, there are indications that after teaching is completed, preparations usually tend to drift to larger taper angles than have been taught. $^{3}$

In the past, feedback from undergraduates at this Institute has sometimes reported the difficulty of visual appreciation of the methods taught in the Introduction to Clinical Practice Course. In particular, it was declared that the lectures and handouts were helpful but needed practical clarification on technical features of the FVC preparation such as taper. It was also admitted that it was difficult to see sufficient detail during demonstrations in groups.

This study was an investigation into the effects on undergraduate learning processes of an improved understanding of the value of taper on preparations early in the teaching programme. The enhanced understanding was provided by improved visualisation with the use of a surgical microscope with attached video camera that displayed a real time magnified image on a high quality television monitor. This arrangement allowed video recording and subsequent replay at the end of the lesson or on another teaching occasion if required. The imaging system magnified the selected region of interest and produced high quality, detailed, close-up pictures that demonstrated the preparation and particularly illustrated the value of the taper and the size of the chamfer that form a central part of the FVC preparation.

\section{Method}

Comparative Group Teaching Experiment In this study, the complete annual cohort of 49 undergraduate for the year 1996 received a lecture and a handbook demonstrating the principles of retention for extra-coronal preparations. The annual cohort was divided randomly into four groups. In these groups, undergraduates were shown how to make the FVC preparation by teaching staff. Three of the groups, A (consisting of $n=12$ undergraduates), $B(n=12)$ and $C(n=12)$ received conventional instruction without the use of visual aids. For the fourth group D $(n=13)$, the teaching was supplemented using real time images of the FVC preparation process displayed on a large colour display monitor. Each of the four groups received instructional periods of equal duration from two teachers on separate occasions and these teachers were not changed during the course. Additional preparations were examined after one month and one year later.

The first set of measurements were taken from the undergraduate's first full crown preparation. This preparation was only attempted after several practices and considerable supervisory assistance. The sec- 
ond and third sets of measurements were recorded one month and one year later from new preparations from all groups of students. These later preparations were each performed without assistance within one hour.

The fourth set of measurements were recorded from the first full preparations of the following new year's cohort of undergraduates $(n=52)$, also grouped at random $(4 \times 13)$ none of whom were taught using the surgical microscope.

\section{Production of Real Time Video Image} The video image was generated using a DP 1010 (DP Medical Systems, Epsom, UK) video camera attached to a Global Surgical Microscope (Global Surgical Microscope, St Louis, USA) focused on the demonstration workpiece. The image monitor used was a $89 \mathrm{~cm}$ Sony Trinitron (type PVM295OQM) and was viewed by the class at a distance of about $3 \mathrm{~m}$ (Figure 1). The microscope was mobile and had an inclinable binocular eyepiece, with a fine focus device and virtual beam splitter. The video camera was used at $\times 10$ magnification. A HiDi 504

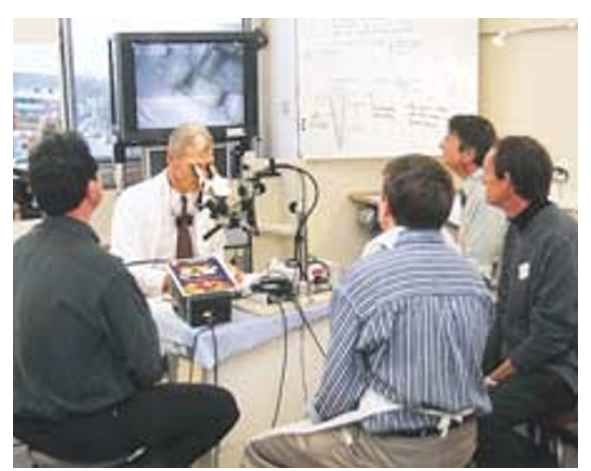

Figure I. The video image was generated by a video camera attached to a Global Microscope focused on the demonstration workpiece. The undergraduates viewed the enlarged image at a distance of about $3 \mathrm{~m}$.

(Dentsply, Weybridge, UK) tapered domedended diamond point was used by the undergraduates to prepare the taper and preparation chamfer.

\section{Measurement of Taper}

All undergraduates were taught the stan- dard way of estimating the taper during preparation. This was by viewing the axial walls and cavo-surface angle of the preparation with one eye. Using this technique, a taper of 7 degrees (approximately 3.5 degrees on each side of the path of insertion) would be indicated when both axial surfaces were just visible from a distance of about $30 \mathrm{~cm}$. This enabled the undergraduates to monitor their samples during preparation. After preparation, taper was measured. Measurements of the taper between the mesial and distal surfaces were taken from the four separate preparations.

A jig was built to allow a reproducible presentation of the prepared teeth to the measurement system (Figure,2). The apparatus enabled rotation of the preparation to pro-

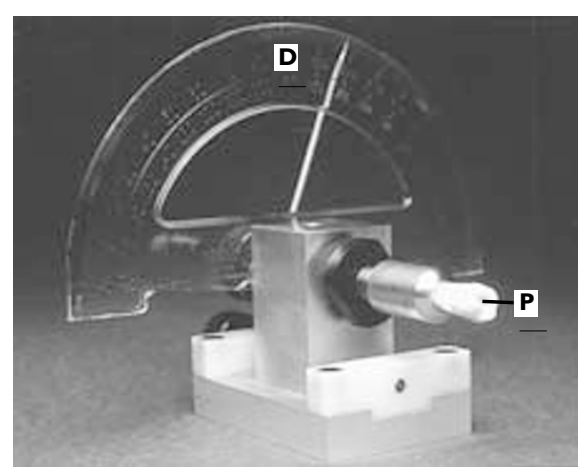

Figure 2. Each preparation $\mathbf{P}$, was held in a jig and rotated to produce the optimum image of the mesial and distal surfaces. The scale $D$ on the apparatus assisted the operator to find the optimum image.

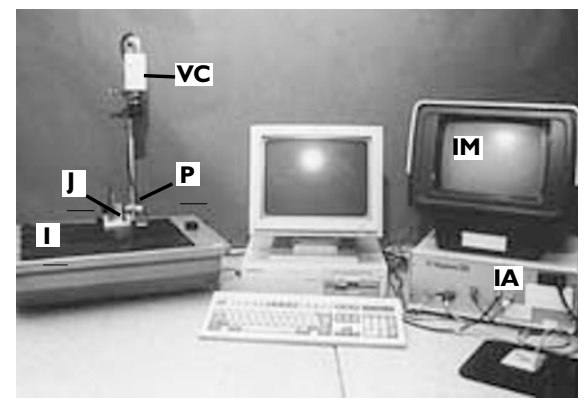

Figure 3. Photograph showing the arrangement of the apparatus for estimating taper. J, jig for holding each preparation, $P$ preparation, I illumination, VC video camera, IM image analyser monitor, IA, image analyser. vide an optimal image of the mesial and distal surfaces. The degree of rotation was indicated by a pointer on a dial. The samples were illuminated from below and the CCD camera (NEC Tl-22C) was mounted vertically to obtain the required image (Figure 3). This was acquired and stored.

The image analyser used for the angle measurement comprised a commercially available frame grabber (Carr Crouch Computer Company, Maidenhead, UK) based on Motorola 68020/68881 microprocessors interfaced to an IBM-compatible PC. The operation of the system was controlled via the keyboard of the PC and all software was written in 'C'. The software developed for this application allowed the acquisition and storage of the entire image of the field of view in the memory of the frame grabber. The resolution of the stored image was 512 $\times 512 \times 6$ bits and the software also enabled the definition of the contours of interest and the measurement of the specified angles. As

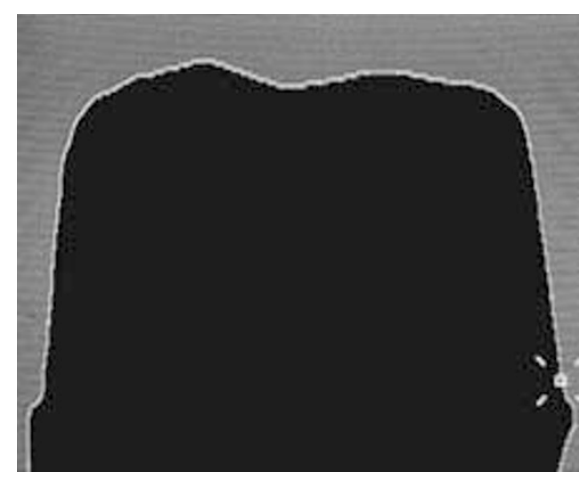

Figure 4 Processed outline of a preparation, shown as a white line, and the star shaped cursor positioned at one limit of the surface contributing to the taper between the mesial and distal surfaces.

an illustration of the processing, Figure 4 shows the outline of a preparation as presented on the image analyser monitor. The outline of the tooth surface is white and the star-shaped cursor illustrated was used to identify the parts of the contour to be considered for angular measurement.

Ten measurements of each tooth preparation were made, repositioning the sample for an optimal image before each measurement to show the most representative out- 


\section{EDUCATION restorative dentistry}

\begin{tabular}{|c|c|c|c|c|}
\hline Table I & \multicolumn{4}{|c|}{$\begin{array}{l}\text { Values for mesio-distal taper and deviation from the ideal taper of } \\
\text { seven degrees for undergraduate's FVC preparations }\end{array}$} \\
\hline Group & First FVC taper & After I month & After I year & $\begin{array}{l}\text { New cohorts' } \\
\text { first FVC taper }\end{array}$ \\
\hline A & $\begin{array}{l}15.13 \pm 2.8 \\
8.13 \pm 2.8\end{array}$ & $\begin{aligned} 17.13 & \pm 3.54 \\
9.13 & \pm 2.5\end{aligned}$ & $\begin{array}{l}16.90 \pm 4.0 \\
8.80 \pm 3.0\end{array}$ & $\begin{array}{l}14.91 \pm 2.7 \\
9.13 \pm 2.9\end{array}$ \\
\hline B & $\begin{array}{l}14.85 \pm 1.9 \\
8.85 \pm 1.9\end{array}$ & $\begin{array}{l}18.04 \pm 4.04 \\
10.05 \pm 4.0\end{array}$ & $\begin{array}{l}18.58 \pm 3.23 \\
\quad 9.5 \pm 2.2\end{array}$ & $\begin{array}{l}15.61 \pm 1.8 \\
8.01 \pm 2.0\end{array}$ \\
\hline C & $\begin{array}{l}14.51 \pm 1.6 \\
8.50 \pm 1.6\end{array}$ & $\begin{array}{l}17.92 \pm 4.1 \\
9.92 \pm 3.1\end{array}$ & $\begin{array}{l}17.20 \pm 4.2 \\
8.20 \pm 2.2\end{array}$ & $\begin{array}{c}15.65 \pm 1.7 \\
9.79 \pm 1.6\end{array}$ \\
\hline$D$ & $\begin{array}{l}9.09 \pm 1.9 * \\
3.96 \pm 1.6 *\end{array}$ & $\begin{array}{c}11.97 \pm 3.4^{*} \\
5.99 \pm 2.0^{*}\end{array}$ & $\begin{array}{c}12.75 \pm 3.5^{*} \\
5.65 \pm 2.5^{*}\end{array}$ & $\begin{array}{c}15.99 \pm 2.2 \\
8.93 \pm 2.9\end{array}$ \\
\hline \multicolumn{5}{|c|}{ *p $<0.001$ compared with Groups A, B and C } \\
\hline \multicolumn{5}{|c|}{$\begin{array}{l}\text { The Table shows the mesio-distal crown tapers } \pm \text { SD (bold) for the year } 1996 \text { undergraduates' first preparation and } \\
\text { further preparations at I month and after I year for all Groups. The tapers for the following new, } 1997 \text { undergraduates } \\
\text { are shown in the right column. The new undergraduates were not taught with the microscope. }\end{array}$} \\
\hline \multicolumn{5}{|c|}{$\begin{array}{l}\text { The values in italics show the mean deviation from seven degrees for Groups A, B, and C compared with Group D, } \\
\text { taught with the microscope. }\end{array}$} \\
\hline
\end{tabular}

line of the mesial and distal surfaces. A different operator unconnected with the study who was unaware of the reason for the measurements measured the tapers a second time. The normality of the data was tested using the Kolmogorov-Smirnov test. The mean taper for the groups and the deviation from the ideal taper of seven degrees was calculated and this was compared between the groups using Student's test.

In general, frame grabbers do not produce digitised images with aspect ratio 1:1.
Therefore, the resolution in the $\mathrm{x}$ and $\mathrm{y}$ directions is not the same, leading to nonsquare pixels. This affects the measurement of angles and distances. Therefore a calibration procedure was used to ascertain the accuracy of image measurement.

\section{Calibration Procedure}

A set of 36 truncated brass cones was manufactured covering a range from -10 to +25 degrees of taper. An example - that of +12 degrees of taper - is shown in Figure.5.

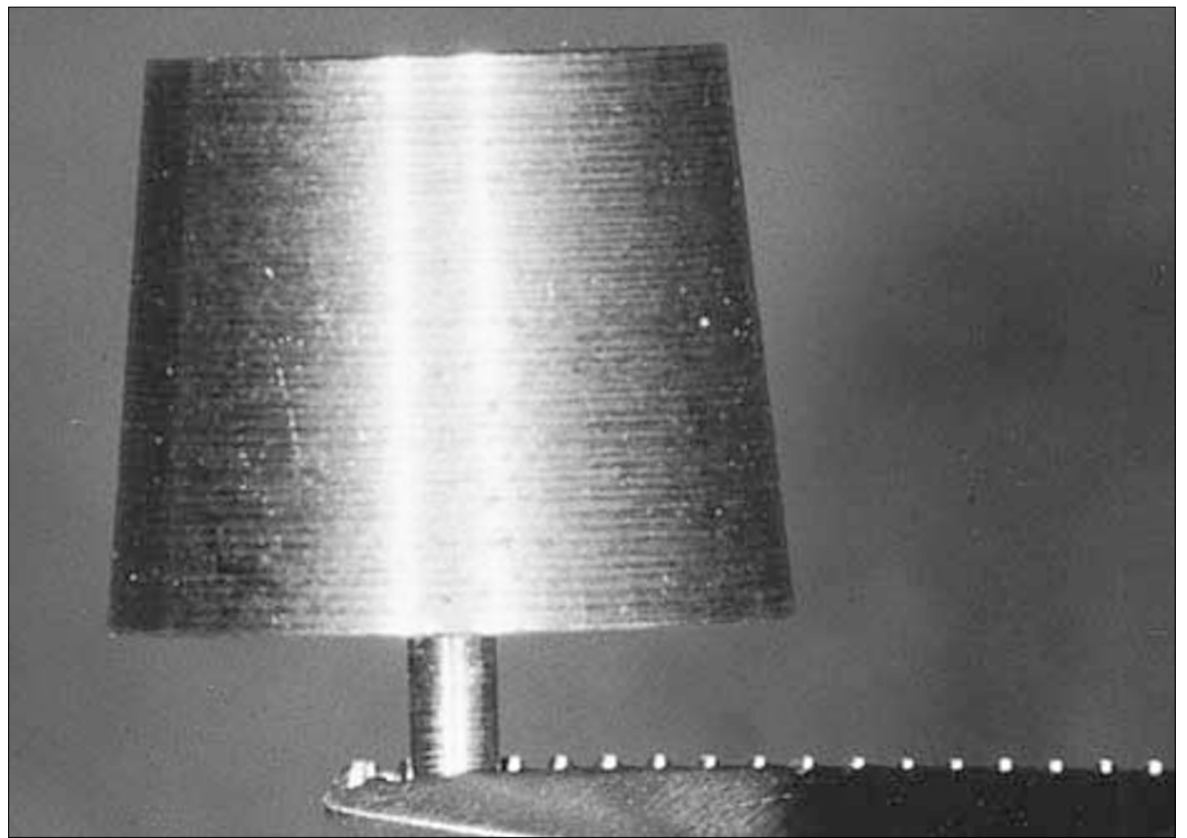

Figure 5 An example of a specially prepared brass cone used with a profilometer to calibrate the measuring equipment. The cone shown has a taper of twelve degrees.

The tapers of the cones were measured accurately using a Nikon Profilometer (calibrated standard instrument) and also with the image analyser. Measurements were taken as accurately as possible for each method and the average of five readings was recorded for each of the cones measured, the object being adjusted by rotation between each separate measurement. This enabled a system accuracy of \pm 0.5 degrees to be quoted for all measurements. The larger number of measurements taken (ten as opposed to five) when measuring the prepared teeth compared with the calibration procedure was due to the variability in slope of some of the samples and hence the increased variability of the sample measurements over those of the calibration pieces.

\section{Results}

The results from the profilometer showed that the raw readings from the image analyser could be used directly and no conversion factor or interpolation was necessary. This is not usual for such devices, but the instrument in question was designed specifically for metrological application.

There was no significant difference (at the 5 per cent level) between the two sets of data produced by the two independent operators who performed the measurements. All groups tended to exaggerate the taper, but Group D, taught with the microscope to make the technique preparation, produced a mean taper significantly lower $(\mathrm{p}<0.001)$ than the other groups taught without the microscope for the first preparation FVC, (Table 1). This improvement was maintained at one month and one year later after 
the undergraduates had carried out clinical procedures that sometimes included gold alloy restorations. The mean taper of the following new year's cohort of undergraduate students (first FVC) taught without magnification was approximately 14 degrees (varying between 14.91 and 15.99 see Table 1 ). This taper was not significantly different compared with the taper on the first preparations Groups A, B and C. The improved performance of group D was indicated by the smaller deviation from the chosen ideal of no more than 7 degrees (Table 1).

There were no undercuts on preparations between the mesial and distal surfaces for any of the first preparations that were supervised. Six preparations prepared by the students at one month and one year later, two from group $\mathrm{D}$, had undercuts between the mesial and distal surfaces.

\section{Discussion}

There is a general acceptance of the value of new technology such as the surgical microscope and the use of videos for teaching postgraduates, ${ }^{4}$ particularly in the field of endodontics. However, searches of the literature suggest that such equipment has not been used to enhance education at the preclinical level. For undergraduate education it appears that conventional methods still prevail although teaching using live television has been used, ${ }^{5}$ as have interactive live television, ${ }^{6}$ pre-recorded videos, ${ }^{7}$ videos for re-visualisation of clinical situation ${ }^{8}$ and multimedia live distant learning. ${ }^{9}$ The use of CCTV is now becoming increasingly common particularly at this institute for many disciplines, especially in oral surgery. However, traditional methods still largely prevail for the teaching of the finer details of restorative dentistry at the undergraduate level. These include demonstration by a teacher of an exercise, often with the use of models to a small group of undergraduates, preceded by a standard lecture along with handouts. However, in these situations it is often difficult for an undergraduate to see the demonstrations effectively especially when the groups are large and when the procedures involve fine detail. It appears, therefore, that there may be a role in this dis- cipline for the production of live, real time, high quality coloured magnified images with the facility for video playback. These would include the ability to demonstrate the taper on FVCs, a feature on the preparation that is difficult to demonstrate without magnification. In addition, detail such as taper may be illustrated by alignment of the bur to surfaces on the preparation. This may indicate the production of an undercut and the appearance of the actual value of taper required without the teacher being required to draw diagrams.

Unfortunately, experiments of this kind may unintentionally give rise to the socalled Hawthorne Effect. ${ }^{10,11}$ This was named after the plant of the Western Electric Company near Chicago where experiments in the 1920s to understand the influence of working conditions on workers led to confusing results. It was found that when subjects were aware of being part of an investigative study, their performance could be affected. In the study reported in this paper, undergraduates of group D were presented with different teaching methods compared with the other groups and were aware of the 'special attention' they were receiving. This could have led to an improvement in performance. The 'special attention' could be postulated to be due to either the teacher's enthusiasm or increased attention to detail or from the use of the microscope irrespective of the magnification and improved visibility it provided. Unfortunately there is considerable controversy about the exact nature and recommended control methods with regard to the Hawthorne Effect ${ }^{12}$ and its contribution is difficult to estimate. Nevertheless, the improvement in performance in this study was not short lived as may be reported for the Hawthorne Effect and was maintained over a year. This demonstrates that the teaching method reported was more effective than the traditional techniques and has been adopted in this institute. We will continue to monitor the performance of the undergraduates for the reasons above.

Textbooks and, in particular, teachers' illustrations often exaggerate taper on preparations designed to receive gold alloy restorations. It is very difficult to draw lines with a seven degree taper that demonstrate the correct angle without introducing an undercut and sketched diagrams often exaggerate taper. This may give the undergraduate a misconception about the visualisation of seven degrees at the outset. Use of the microscope allowed the undergraduates to improve their ability to critically evaluate taper. The fact that after 1 year, 2 of the 6 undercut teeth prepared were from Group D means that this experimental group had at least as many undercuts as one group and more undercuts than two of the other groups. This finding may suggest that the increased magnification and the use of the microscope may have led to the pitfall of creating preparations with too little taper or even undercuts that are a much more serious problem than a few degrees of over taper. However, if this were the case, it is regarded as more likely that Group D would have produced far more undercuts than recorded since they had less margin for error than the other groups working at greater tapers.

\section{Conclusion}

This study indicates that improved performance was achieved by the use of real time video magnification during the teaching process. Furthermore the video recording produced during the class was available for subsequent display during a classroom session. These preliminary findings suggest that undergraduates' initial understanding, or first impression of the problem, at the earliest stage when they are acquiring skill is critical. This early understanding may have significant consequences on their future development in operative dentistry, not only for the evaluation of taper but other aspects of preparation design. This method of teaching maintains teacher-undergraduate communication by allowing instant feedback and encourages the feeling that reality that may be lost by reliance on the use of a video recording alone. The surgical microscope with attached video camera, being easy to use, does not require extensive training by the operator.

Currently, the use of visual aids in teaching dentistry is increasing dramatically. The main application of video is in the produc- 


\section{EDUCATION restorative dentistry}

tion of distance learning courses. Here the video is produced as a 'potted' lecture, which either forms the entire course or is used to back-up an existing course as a revision aid, for example. The disadvantages of these applications are the time and expense to produce them and in the difficulty of amending and updating the product. ${ }^{13}$ The product also lacks interactivity that is generally regarded as essential for detailed or advanced subjects. This paper is concerned with the use of real-time video as a support aid for conventional teaching. There is evidence $^{14}$ that this is fairly common, but, to the authors' knowledge there are no reports of benefits to teaching other than by undergraduate feedback or other anecdotal evidence. Here we attempt to demonstrate quantitatively that benefits may be achieved using these methods. As far as magnification is concerned, there are many areas in medicine where this is essential to the procedures, for example, in microsurgery, but the use of microscopy as a general aid to vision in dental surgery has been reported to be difficult to justify. ${ }^{15}$ This paper is only concerned with use of visual aids in teaching. It is not conceived that practitioners would use either magnification or video or perform the procedures in practice.

The authors are indebted to Dr D Cooper, Head of the Computer Services Unit at Guy's, King's and St. Thomas's School of Medicine for assistance with the statistics used in this manuscript. Thanks are also due to DrD Fenner of the Department of Mechanical Engineering, KCL, for access to the Nikon Profilometer, and to DrS Dunne of the Department of Conservative Dentistry, Guy's, King's and St.Thomas's Dental School for the provision of the brass cones used for calibration.

1 Rosenstiel E. The taper of inlay and crown preparations. Br Dent J 1975; 139: 436-438.

2 Shillingberg H, Hobo S, Whitsett L D, Jacobi R, Brackett S E. Fundamentals of fixed prosthodontics 1997. Chicago; Quintessence.

3 Dodge W W, Weed R M, Ramon J B, Buchanan R N. The effect of convergence angle on the retention and resistance form. Br Dent J 1994; 176: 381-384.

4 Knowles K I, Ibarrola J L, Ludlow M O. The dental operating microscope as an educational tool. I Dent Ed 1998; 62: 429-431.

5 Stevens L. A comparison of two methods of demonstrating an exercise in dental technology. Aus Dent J 1977; 2: 281-283.

6 Brown C P M. Interactive live television in clinical dental teaching. Br Dent J 1984; 156: 371-372.
7 Holt R D, Rule D C, Basker R M, Davenport J $\mathrm{C}$ et al. The influence on partial denture design of a teaching video for general dental practitioners. Br Dent J 1994; 176: 379-385.

8 Roberts D B. Clinical teaching by videoenhanced Study Club Discussion Sessions. J Dent Ed 1988; 52: 214-216.

9 Bates W. Educational multimedia in a networked society. In Ottman T Tomek I (eds) Educational multimedia and hypermedia, Proceedings of the world conference of educational multimedia 1994. Charlottesvillle Va. Association for the Advancement of computing in education.

10 Ball S. Unintended effects in educational research. In Husen T, Postlewaite TN (eds) International Encyclopaedia of Education 1994 Vol 11; 2nd ed. London; Pergamon.

11 Gall M D, Borg W R, Gall J P. Educational research: An introduction 1996. 6th ed. New York. Longman.

12 Diaper G. The Hawthorne Effect: a fresh examination. Educational studies 1990; 16: 261-267.

13 Nattestad A, Affstrom A. Information technology in oral health education. Eur J Dent Educ. 1997; 1: 101-118.

14 Suvinen T I, Messer L B, Franco E. Clinical simulation in teaching preclinical dentistry. Eur. J Dent Educ 1998; 2: 25-32.

15 Donaldson M E, Kurzht G W Guenzel P J. The effect of magnification on student performance in pediatric operative dentistry. $J$ Dent Educ 1998; 62: 905-910. 